Gut, 1976, 17, 933-939

\title{
Responses of the competent and incompetent lower oesophageal sphincter to pentagastrin and abdominal compression
}

\author{
M. D. KAYE 2 , R. REIN, W. P. JOHNSON, AND J. PHILIP SHOWALTER \\ From the Department of Medicine, University of Vermont, Burlington, Vermont, and the Department of \\ Medicine, University of Colorado, Denver, Colorado, USA
}

SUMMARY Responses of the lower oesophageal sphincter (LOS) to pentagastrin, given by continuous intravenous infusion in doses ranging between 0 and $9 \mu \mathrm{g} / \mathrm{kg} / \mathrm{h}$, and to external abdominal compression were measured by infused catheters in healthy subjects and in a group of patients with reflux oesophagitis. In separate experiments, pressures were measured both by sensors stationary within the LOS, and by repeated continuous withdrawals of sensors from stomach to distal oesophagus. In normal subjects, doses of pentagastrin within the physiological range $(0.9 \mu \mathrm{g} / \mathrm{kg} / \mathrm{h})$ produced modest but statistically significant increases in LOS pressure. By comparison, sphincteric responses in patients with oesophagitis were small and a dose of $4.5 \mu \mathrm{g} / \mathrm{kg} / \mathrm{h}$ was the lowest that produced a significant increase in LOS pressure. During abdominal compression increases in LOS pressure did not significantly exceed increases in intragastric pressure in either patients or normal subjects. This was so at all doses of pentagastrin that were tested. Hence, there was no evidence of synergism between the effects of pentagastrin and abdominal compression upon the LOS. We infer from our findings that gastrin does play a modest role in the physiological regulation of human LOS tone. Relative insensitivity of the incompetent LOS to pentagastrin represents, we believe, sphincteric muscle failure. Our results are not consistent with the hypothesis that LOS incompetence is due to loss or impairment of an adaptive response of the LOS to alterations in intra-abdominal pressure.

The central role of the physiological lower oesophageal sphincter (LOS) in the prevention of gastro-oesophageal reflux is now well recognised; and, in recent years, the effects upon resting LOS pressure of a number of hormones and drugs have been defined (Castell, 1975). However, the physiological means by which resting pressure within the LOS is maintained and modulated have not been fully elucidated; nor have the factors responsible for sphincteric incompetence, and therefore gastro-

\footnotetext{
'This work was supported by Research Grants AM 15952 , AM 18217; by General Research Support Grant funds; and by grants (RR-51 and RR-109) from the General Clinical Research Centers Program of the Division of Research Resources; National Institutes of Health, Bethesda, Maryland, USA.

Address for reprint requests; Dr Michael D. Kaye, C321 Given Medical Building, University of Vermont, College of Medicine, Burlington, Vermont 05401, USA.

Received for publication 14 July 1976
}

oesophageal reflux, been clearly identified. The demonstrations that human LOS pressure could be modified by gastric infusions of acid and alkali (Castell and Harris, 1970; Beiles et al., 1972; Castell and Levine, 1972; Higgs et al., 1974); that LOS pressure could be consistently increased by gastrin and pentagastrin (Giles et al., 1969; Castell and Harris, 1970; Cohen and Lipshutz, 1971; Lipshutz et al., 1973; Siewert et al., 1974; Trindade et al., 1975); and that LOS pressure in the opossum could be drastically diminished by the use of gastrin antiserum (Lipshutz, et al., 1972) led to the proposal that gastrin was of primary importance in the regulation of LOS pressure. Recent studies, however, have cast considerable doubt upon the physiological relevance of gastrin in this context (Grossman, 1973; Sturdevant and Kun, 1973; Farrell et al., 1974; Goyal and McGuigan, 1975; Walker et al., 1975).

It is well established that LOS pressure rises 
when intra-abdominal pressure is increased (Fyke et al., 1956; Nagler and Spiro, 1961; Van Derstappen and Texter, 1964; Lind et al., 1966; Cohen and Harris, 1971; Henderson and Rodney, 1971; Dodds et al., 1975b) and several groups, having found that the rise in pressure in the LOS exceeds that in the stomach, have concluded that this LOS response is adaptive and perhaps neurally mediated rather than purely mechanical. Moreover, Cohen and Harris (1971), who reported that the LOS pressure rise exceeded the gastric pressure rise in subjects without symptoms of gastro-oesophageal reflux, but not in those with such symptoms, concluded that a deficient LOS response to altered intra-abdominal pressure might be related pathogenetically to sphincteric incompetence. However, Dodds et al. (1975b) using somewhat different methods, were unable to confirm these findings.

In the experiments here described, the effects of pentagastrin and of increased intra-abdominal pressure, both separately and in combination, were studied in normal subjects and in patients with reflux oesophagitis. Our aims were to determine (1) whether the human LOS responds to 'physiological' doses of pentagastrin, and if so, whether the response of the incompetent sphincter differs from that of the competent one, and (2) whether the response of the LOS to increased intra-abdominal pressure is adaptive, and if so, whether sphincteric incompetence can be related to loss of such an adaptive response. Since conflicting results from studies of LOS function may well be due partly to the use of different methods for pressure measurement, and since there is no general agreement as to the best method, we measured LOS pressures by two different techniques-anchored stationary catheters and repeated continuous withdrawals-in separate series of studies. Moreover, experiments were designed to avoid observer bias in interpretation of manometric tracings.

\section{Methods}

\section{SUBJECTS}

Fully informed written consent was obtained from all subjects studied.

The normal group consisted of healthy young volunteers without symptoms of gastro-oesophageal reflux (heartburn and reflux of sour or bittertasting fluid into the mouth) or of other upper abdominal disorders.

The oesophagitis group was composed of patients with symptoms of gastro-oesophageal reflux, in whom oesophagitis had been documented by endoscopy and/or oesophageal biopsy (using the criteria described by Ismail-Beigi et al., 1970).
None of these patients had undergone hiatal herniography or upper abdominal surgery.

Two series of experiments were carried out. Each series compared 10 normal subjects with 10 patients. The experimental design for the two series was the same except that, in the first, LOS pressure was measured by a catheter system anchored and maintained in the same position with pressure sensors (catheter openings) at the point of maximum pressure within the LOS, whereas, in the second, LOS pressure was measured by repeated withdrawal of the sensors from stomach to oesophagus.

\section{FIRST SERIES: STATIONARY CATHETER} METHOD

The control group consisted of three males and seven females, whose ages ranged from 21 to 32 years (mean 25.2 years). In the patient group there were six males and four females and the age range was from 30 to 68 years (mean 50.6 years). Sliding hiatal hernia and oesophageal stricture were demonstrable in six and one patients, respectively. At the time of study, no patient was receiving any drug known to affect LOS function. After an overnight fast, during which smoking and antacid consumption were proscribed, an assembly consisting of four catheters, each with an ID and OD of $1 \cdot 12$ and $1.65 \mathrm{~mm}$ respectively, was passed through the mouth into the stomach. Three of the catheters were used for measurement of LOS pressure. These had side openings of $1.1 \mathrm{~mm}$ diameter at the same axial level of the assembly. The fourth catheter, whose opening was $7 \mathrm{~cm}$ distal to this point, was used for measurement of intragastric pressures. Catheters were individually perfused with water at a rate of $1.0 \mathrm{ml}$ per minute by means of an infusion pump (Harvard Apparatus Co., Inc.). They were connected to external transducers (Statham P 23 De or Bell and Howell 4-327-1) whose output was graphed on a multichannel recorder (Gilson Macropolygraph). Respiration was monitored by a belt pneumograph which encircled the chest and which was attached to the recorder via a fourth transducer. Swallowing was recorded by electromyograph. An initial profile of the LOS was obtained by stepwise withdrawal, $0.5 \mathrm{~cm}$ at a time, of the catheter assembly from stomach to distal oesophagus. The assembly was then anchored by taping firmly to the cheek, with the openings of the three catheters for LOS pressure measurement at the point of maximum LOS pressure, which was invariably just below the pressure inversion point (point of respiratory reversal). The assembly was maintained in the same position for the remainder of the study. A needle was then inserted into a vein of the hand or forearm and connected by a $\mathrm{Y}$ fitting to two syringes 
which contained sterile normal saline, or pentagastrin (Peptavlon, Ayerst Laboratories, New York, N.Y.) diluted with sterile normal saline. Pentagastrin, in doses of 0 (sterile saline), $0.45,0.9,1.8,4.5$, and $9 \mu \mathrm{g} / \mathrm{kg} / \mathrm{h}$ was then given by means of a constantrate infusion pump (Harvard Apparatus Co., Inc.) during sequential 15 minute infusion periods. The order of doses was randomised. At the end of each infusion period, LOS and gastric pressures were recorded continuously both without abdominal compression ( 0 pressure) and during compression of the abdomen by a wide abdominal pressure cuff inflated to pressures of 15 and $30 \mathrm{~mm} \mathrm{Hg}$. Again, the order of applied pressures $(0,15$, and 30$)$ was randomised. The pressure tracings obtained were analysed by a computer-assisted technique. The person responsible for analysis was unaware of the order in which the doses of pentagastrin had been given.

\section{SECOND SERIES: CONTINUOUS PULLTHROUGH} METHOD

The control group consisted of seven males and three females, whose ages ranged from 19 to 31 years (mean 24.5 years); and the patient group of four males and six females, with an age range of 28 to 74 years (mean 52.7 years). Six and five of these patients had a sliding hiatal hernia and oesophageal stricture, respectively. These experiments differ from those of the first series in the following respects:

1. A triple lumen assembly was used. Catheters had side openings at the same axial level of the assembly.

2. LOS pressure measurements were obtained by a continuous withdrawal technique. For each measurement, the recording openings were withdrawn from the stomach to distal oesophagus at a rate of $1 \mathrm{~cm} / \mathrm{s}$ by means of a device similar to that described by Waldeck (1972). During withdrawals, subjects held their breath at the end of a tidal respiration. They were instructed not to swallow during, and for 30 seconds before withdrawal. Measurements were repeated if swallowing occurred, if breathholding was unsatisfactory, or if there was evidence of a Valsalva manoeuvre. On some occasions in patients with oesophagitis, an LOS pressure profile was not recorded during abdominal compression due to sphincteric incompetence and formation of a common cavity. In these instances, also, pullthroughs were repeated.

3. During LOS pressure measurements, each catheter was infused with water at a rate of $4 \mathrm{ml} / \mathrm{min}$.

Apart from these differences, the design of experiments was the same as in the first series.

For studies in the first series (catheters stationary),
LOS pressure, in $\mathrm{mm} \mathrm{Hg}$, was measured in relation to the initial gastric fundal baseline pressure. For simplicity, only end-inspiratory pressures are presented, though, in fact, results are similar when expressed in terms of end-expiratory or midrespiratory pressures. A given measurement represents the mean of the three recordings at the same axial level, measured for a period of approximately 30 seconds. Effects of abdominal compression upon intragastric pressure were recorded by the fourth catheter, whose opening was in the proximal stomach. For studies in the second series, in which LOS pressure was measured by a continuous pullthrough during suspended respiration, LOS pressure was determined as the rise above the baseline gastric pressure recorded at the beginning of each pullthrough; and, again, a given measurement represents the mean of values obtained simultaneously from three separate pressure sensors.

\section{Results}

\section{EFFECT OF PENTAGASTRIN}

First series: stationary catheter method

LOS pressures in response to different doses of pentagastrin, without abdominal compression are

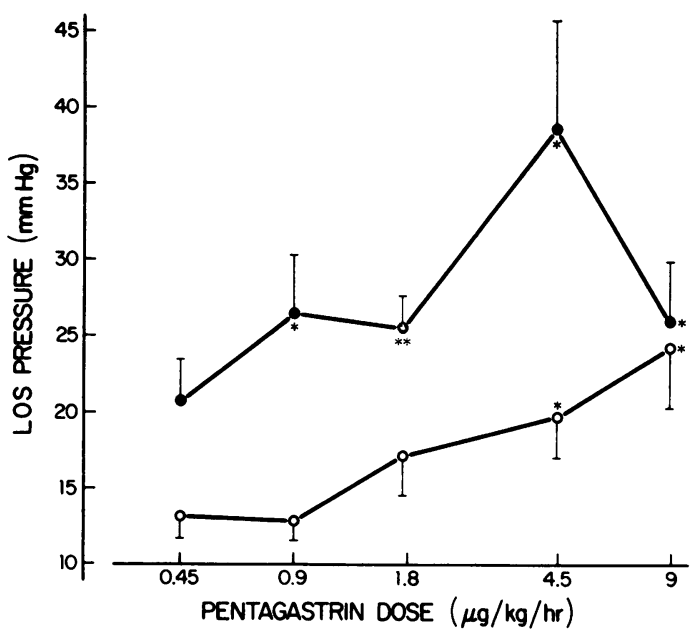

Fig. 1 LOS pressures during pentagastrin infusion, without abdominal compression, in normal subjects (O) and patients with oesophagitis (O). Pressure sensors stationary within LOS (first series of experiments). Means and standard errors are shown. Values significantly different from control, without pentagastrin, (18.01 \pm 2.69 and $15.05 \pm 1.36$ in normal subjects and patients respectively) are indicated by asterisks $\left({ }^{*} \mathrm{P}<0.05\right.$, ${ }^{* *} \mathrm{P}<0.005$, Student's t test for paired data, onetailed). 
shown in Fig. 1. For the normal group, significant rises in pressure occurred with $0.9 \mu \mathrm{g} / \mathrm{kg} / \mathrm{h}$ of pentagastrin, and the peak response, which represented a $114 \%$ increase over the basal value, occurred with $4.5 \mu \mathrm{g} / \mathrm{kg} / \mathrm{h}$. By contrast, in the patient group, only the 4.5 and $9 \mu \mathrm{g} / \mathrm{kg} / \mathrm{h}$ doses had a significant effect upon LOS pressure, and the maximal increase, of $62 \%$ over the basal value, occurred at $9 \mu \mathrm{g} / \mathrm{kg} / \mathrm{h}$.

\section{Second series: continuous pullthrough method}

Results, shown in Fig. 2, were similar. Again, in the normal group a significant effect of pentagastrin was demonstrated with a dose of $0.9 \mu \mathrm{g} / \mathrm{kg} / \mathrm{h}$, and the peak response, of $69 \%$, occurred with the $4.5 \mu \mathrm{g} / \mathrm{kg} / \mathrm{h}$ dose. Small rises in LOS pressure occurred with $1 \cdot 8,4 \cdot 5$, and $9 \mu \mathrm{g} / \mathrm{kg} / \mathrm{h}$ doses in the patient group, but the changes were not statistically significant $(P>0.2)$ with any dose.

\section{EFFECTS OF INCREASED INTRA-ABDOMINAL} PRESSURE (IIP) UPON LOS PRESSURE

Intragastric pressure regularly increased in response to abdominal compression. As we wished to determine whether rises of pressure in the LOS exceeded those in the stomach, each LOS pressure

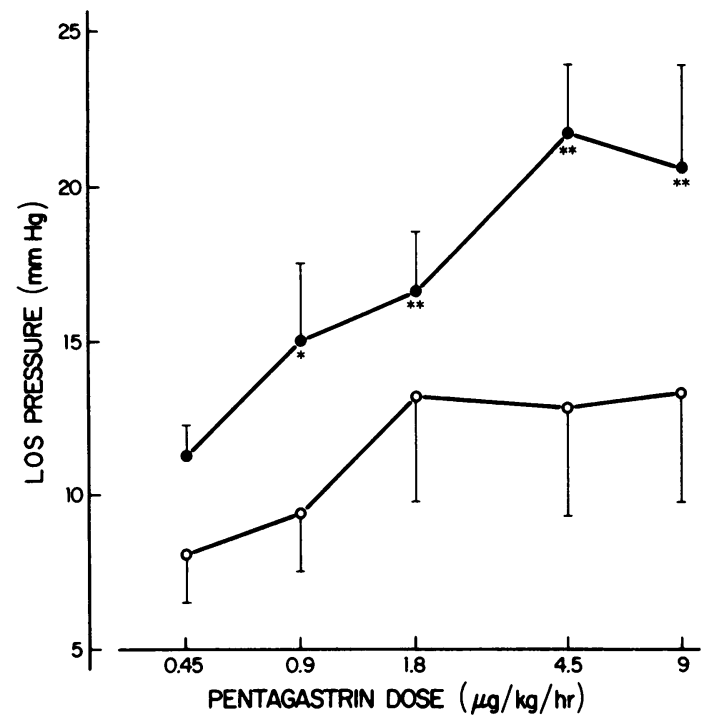

Fig. 2 LOS pressures during pentagastrin infusion without abdominal compression, in normal subjects (O) and patients with oesophagitis $(\bigcirc)$. Pressures measured by continuous withdrawal technique (second series of experiments). Means and standard errors are shown. Values significantly different from control, without pentagastrin $(9.80 \pm 0.94$ and $9.39 \pm 1.94$ in normal subjects and patients respectively) are indicated by asterisks $\left({ }^{*} \mathrm{P}<0.025,{ }^{* *} \mathrm{P}<0.001\right)$. measurement obtained during abdominal compression was corrected by subtraction of the rise in gastric pressure which had been simultaneously recorded. The resulting value could then be compared with that obtained without abdominal compression and with the same dose of pentagastrin.

\section{First series: stationary catheter method}

Rises in intragastric pressure during inflation of the abdominal cuff of $15 \mathrm{~mm} \mathrm{Hg}$ were $4.42 \pm 2.09$ (mean \pm SD) and $5.33 \pm 2.05$ in controls and patients respectively. During inflation of the cuff to $30 \mathrm{~mm} \mathrm{Hg}$, the corresponding values were $9.32 \pm 3.13$ and $9.92 \pm 3.60$. The difference between groups for the $15 \mathrm{~mm} \mathrm{Hg}$ values was significant $(\mathrm{P}<0.02$, Student's $t$ test for unpaired data, two-tailed). The reason for this difference is uncertain, although it may reflect relative laxity of the abdominal musculature in patients, as compared with healthy subjects. Differences between LOS pressures without abdominal compression, and corrected LOS pressures during compression, are shown in Table 1. In no instance were the measurements during compression significantly higher than those without compression-that is to say, in no case did the mean rise in LOS pressure $(\Delta$ LOS) exceed the mean rise in intragastric pressure $(\Delta \mathrm{G})$. In both groups, $\Delta$ LOS tended to be less than $\Delta \mathrm{G}$; and in the patient group LOS pressures during

Table 1 Changes in LOS pressures during abdominal compression: pressure sensors stationary within LOS (first series of experiments)

\begin{tabular}{|c|c|c|c|}
\hline \multirow[t]{2}{*}{$\begin{array}{l}\text { Pentagastrin } \\
\text { dose }(\mu \mathrm{g} / \mathrm{kg} / \mathrm{h})\end{array}$} & \multirow[t]{2}{*}{$\begin{array}{l}\text { Pressure } \\
\text { applied } \\
(\mathrm{mm} \mathrm{Hg})\end{array}$} & \multicolumn{2}{|c|}{$\begin{array}{l}\text { Change in gastric-LOS pressure } \\
\text { gradient with compression } \\
\text { (mean } \pm S E, m m \mathrm{Hg})\end{array}$} \\
\hline & & Normal subjects & $\begin{array}{l}\text { Patients with } \\
\text { oesophagitis }\end{array}$ \\
\hline 0 & $\begin{array}{l}15 \\
30\end{array}$ & $\begin{array}{l}+1.60 \pm 3.05 \\
+1.30 \pm 4.49\end{array}$ & $\begin{array}{l}-2.61 \pm 1.44 \\
-4.40 \pm 1.99 \dagger\end{array}$ \\
\hline 0.45 & $\begin{array}{l}15 \\
30\end{array}$ & $\begin{array}{l}+1.24 \pm 3.05 \\
-5.23 \pm 4.38\end{array}$ & $\begin{array}{l}-2.94 \pm 3.80 \dagger \\
-4.85 \pm 1.27 \ddagger\end{array}$ \\
\hline 0.9 & 15 & $\begin{array}{l}-4.08 \pm 4.14 \\
-7.24 \pm 5.54\end{array}$ & $\begin{array}{l}-0.35 \pm 1.56 \\
-\quad 2.92 \pm 1.82\end{array}$ \\
\hline 1.8 & $\begin{array}{l}15 \\
30\end{array}$ & $\begin{array}{l}+0.68 \pm 3.26 \\
-0.33 \pm 4.10\end{array}$ & $\begin{array}{l}-3.68 \pm 1.15 \dagger \\
-8.31 \pm 1.85 \ddagger\end{array}$ \\
\hline $4 \cdot 5$ & $\begin{array}{l}15 \\
30\end{array}$ & $\begin{array}{l}-2.54 \pm 2.88 \\
-11.12 \pm 5.03\end{array}$ & $\begin{array}{l}+1.69 \pm 4.27 \\
-4.70 \pm 3.53\end{array}$ \\
\hline $9 \cdot 0$ & $\begin{array}{l}15 \\
30\end{array}$ & $\begin{array}{l}+7 \cdot 35 \pm 4.74 \\
-0.14 \pm 5 \cdot 18\end{array}$ & $\begin{array}{l}-7.90 \pm 2.82 \dagger \\
-12.80 \pm 3.83+\end{array}$ \\
\hline $\begin{array}{l}\text { All doses } \\
\text { combined }\end{array}$ & $\begin{array}{l}15 \\
30\end{array}$ & $\begin{array}{l}+0.90 \pm 1.44 \\
-3.79 \pm 1.96\end{array}$ & $\begin{array}{l}-2.22 \pm 1.01 \dagger \\
-6.38 \pm 1.08+\end{array}$ \\
\hline
\end{tabular}

*Values represent differences between LOS pressures without compression, and LOS pressures during compression after correction by subtraction of associated rise in intragastric pressure. A positive value indicates that corrected LOS pressures were higher with compression than without; a negative value the reverse.

$\dagger$ Difference between values with and without compression significant at 0.05 level.

$\ddagger$ Differences significant at $\mathbf{0 . 0 0 5}$ level (Student's $t$ test for paired data, two-tailed). 
compression were significantly less than those without compression for seven of 12 measurements (two compression pressures, six pentagastrin dosages).

\section{Second series: continuous pullthrough method}

Results were essentially similar. With $15 \mathrm{~mm} \mathrm{Hg}$ external compression, intragastric pressure rises were $3.99 \pm 1.80$ and $5.70 \pm 2.80 \mathrm{~mm} \mathrm{Hg}$ in controls and patients respectively; and, with $30 \mathrm{~mm}$ $\mathrm{Hg}$ compression, the corresponding values were $8.41 \pm 3.15$ and $9.84 \pm 3.69 \mathrm{~mm} \mathrm{Hg}$. Statistically, the differences between groups were significant ( $\mathrm{P}<0.05$ ) for both the 15 and $30 \mathrm{~mm} \mathrm{Hg}$ measurements.

The effect of abdominal compressions upon LOS pressures is shown in Table 2. Again, $\Delta$ LOS tended to be less than $\Delta \mathrm{G}$ in both groups, with the result that corrected mean values for LOS pressures during compression were generally less than those without compression. Differences between measurements with and without compression were statistically significant in two of 12 sets of measurements in the control group, and one of 12 in the patient group. Results in the patient group were undoubtedly affected by the fact that, not infrequently during abdominal compression, a withdrawal tracing failed to show a LOS pressure profile-that is, a 'common cavity' had been produced, so that LOS and intragastric pressures were equal. In such

Table 2 Changes in LOS pressures during abdominal compression: pressures measured by continuous withdrawal technique (second series of experiments)

\begin{tabular}{llll}
\hline $\begin{array}{l}\text { Pentagastrin } \\
\text { dose }(\mu \mathrm{g} / \mathrm{kg} / \mathrm{h})\end{array}$ & $\begin{array}{l}\text { Pressure } \\
\text { applied } \\
(\mathrm{mm} \mathrm{Hg})\end{array}$ & $\begin{array}{l}\text { Change in gastric-LOS pressure } \\
\text { gradient with compression* } \\
\text { (mean } \pm \mathrm{SE}, \mathrm{mm} \mathrm{Hg})\end{array}$ \\
\cline { 2 - 4 } & & Normal subjects & $\begin{array}{l}\text { Patients with } \\
\text { oesophagits }\end{array}$ \\
\hline 0 & 15 & $+1.82 \pm 1.72$ & $-0.34 \pm 1.62$ \\
& 30 & $+3.66 \pm 3.06$ & $-1.13 \pm 1.93$ \\
0.45 & 15 & $+0.80 \pm 1.97$ & $-0.91 \pm 1.37$ \\
& 30 & $+3.63 \pm 2.31$ & $+0.62 \pm 1.82$ \\
0.9 & 15 & $-2.86 \pm 2.21$ & $+1.16 \pm 2.23$ \\
& 30 & $-5.65 \pm 1.74$ & $-1.61 \pm 1.85$ \\
1.8 & 15 & $-4.28 \pm 1.21 \dagger$ & $-2.95 \pm 1.82$ \\
& 30 & $-4.66 \pm 2.10$ & $-5.40 \pm 2.54$ \\
4.5 & 15 & $-6.41 \pm 2.51 \dagger$ & $-2.11 \pm 0.81 \dagger$ \\
9.0 & 30 & $-4.51 \pm 2.88$ & $-3.90 \pm 2.00$ \\
& 15 & $-2.33 \pm 1.62$ & $-1.46 \pm 3.02$ \\
All doses & 15 & $-5.89 \pm 4.64$ & $-2.29 \pm 1.21$ \\
combined & 30 & $-2.33 \pm 0.83 \dagger$ & $-1.10 \pm 0.77$ \\
\hline
\end{tabular}

*Values represent differences between LOS pressures without compression, and LOS pressures during compression after correction by subtraction of associated rise in intragastric pressure. A positive value indicates that corrected LOS pressures were higher with compression than without; a negative value the reverse.

†Difference between values with and without compression significant at 0.05 level. instances, the measurement was repeated, until a LOS pressure profile was recorded, and the last measurement obtained was used in subsequent analysis.

\section{Discussion}

The design of this study differs in several important respects from others in which the effects of gastrin and pentagastrin upon the human lower oesophageal sphincter have been examined. Firstly, the hormonal agent was given in doses within the physiological range and by continuous intravenous infusion rather than by bolus injection. Secondly, bias was avoided by measurement of pressures without knowledge of pentagastrin doses, the order of which was randomised. Thirdly, LOS pressures were measured by three sensors arranged circumferentially at the same axial level, in order to minimise that variability of pressure measurement which relates to radial orientation of pressure sensors within the LOS (Kaye and Showalter, 1971). And, finally, LOS pressures were measured by two fundamentally different techniques. The validity of our conclusions is strengthened by the similarity of the results obtained with these techniques.

In both series of experiments, pentagastrin was found to increase pressure within the normal LOS at a dose, $0.9 \mu \mathrm{g} / \mathrm{kg} / \mathrm{h}$, which is less than half of that required to produce a maximal gastric secretory response (Multicentre Pilot Study, 1967) and, therefore, well within the physiological range. Hence, it seems reasonable to conclude that gastrin plays some role in the regulation of LOS pressure in normal individuals, though this role may be relatively minor, as the increases in pressure which we observed were quite modest. This view is in accord with the results of some recent studies (Farrell et al., 1974; Wright et al., 1975; Dodds et al., 1975a) which have failed to reveal a clear relationship between levels of serum gastrin and LOS pressure. Moreover, the rise in LOS pressure which occurs in response to a protein mean (Nebel and Castell, 1972; Farrell et al., 1974) does not correlate closely with alterations in concentration of serum gastrin (Farrell et al., 1974; McCall et al., 1975).

As compared with normal subjects, our patients with reflux showed both quantitative reduction in the LOS response to a given dose of pentagastrin, and relative insensitivity to pentagastrin, with displacement of the dose-response curve to the right. These results confirm those obtained by several other groups (Rosenberg and Harris, 1971; Lipshutz et al., 1973; Farrell et al., 1974; Siewert et al., 1974; Sturdevant and Kun, 1974) who have 
compared the responses of the competent and incompetent LOS to pentagastrin. We believe that these abnormalities represent failure of the sphincter muscle. This does not necessarily imply, however, that insensitivity to pentagastrin (or gastrin) is a specific pathogenetic abnormality in schincter incompetence, especially as normal LOS responses to doses of pentagastrin within the physiological range were quite modest.

It is well established that when intra-abdominal pressure rises, so also does LOS pressure. Reports that a given rise in LOS pressure exceeded that rise which occurred simultaneously in intragastric pressure (Lind et al., 1966; Cohen and Harris, 1971) led to the concept of an adaptive, and perhaps neurally mediated, alteration in tone of the intrinsic LOS. Others (Fyke et al., 1956; Nagler and Spiro, 1961; Van Derstappen and Texter, 1964; Henderson and Rodney, 1971), however, have found that induced alterations in intragastric pressure and LOS pressure are similar, suggesting a purely passive response of the LOS to external forces. In probably the most definitive study of this phenomenon (Dodds et al., 1975b) concluded that LOS responses to increased intra-abdominal pressure are best accounted for by purely mechanical factors. They found also, in contrast with Cohen and Harris (1971), that patients with sphincteric competence could not be distinguished from normal on the basis of LOS responses to alterations in abdominal pressure, unless the latter caused development of a 'common cavity' (Butterfield et al., 1972) with complete loss of a gastro-oesophageal pressure gradient. Our findings justify similar conclusions. LOS pressures tended to rise less than intragastric pressures during abdominal compression in both normal subjects and patients with sphincteric incompetence. Interestingly, and despite the fact that the LOS tends to move proximally during abdominal compression (Lind et al., 1966; Dodds et al., 1972), results were the same whether pressures were measured by the continuous pullthrough technique or by sensors held stationary in the LOS. We found no evidence to suggest potentiation by pentagastrin of the LOS response to increased intra-abdominal pressure, and hence no indication of synergism between these two influences. This also is consistent with the hypothesis that the LOS response to alteration in intra-abdominal pressure is purely passive. It should be stressed that our examination of the relationship between induced alterations in intra-abdominal pressure and LOS pressure was limited to a study of the effects of moderate sustained external abdominal compression. Other, less easily controllable methods, such as Valsalva manoeuvre and leg-raising, can be used, and conceivably might have produced different results. Indeed, Dodds et al. (1975b) found that the LOS response exceeded the intragastric pressure response during leg-raising but not during abdominal compression. As perfused catheters within the LOS measure resistance of the wall to stretch, recorded pressures reflect both intrinsic LOS tone and forces applied external to the intrinsic sphincter. Hence, a relatively greater rise in LOS pressure during leg-raising might indicate tighter apposition against the LOS of such structures as the diaphragmatic crura, rather than an adaptive increase in LOS tone. We believe that sphincteric incompetence cannot be held due to failure or impairment of an adaptive LOS response to increased intra-abdominal pressure. It is, however, abundantly clear that episodes of reflux in susceptible individuals do occur during some manoeuvres associated with sudden increases in intra-abdominal pressure. We envisage the incompetent sphincter as one the intrinsic musculature of which is weak, as evidenced by reduced resting tonus and diminished responses to agents such as pentagastrin; inadequately bolstered by external supporting structures; and therefore more readily overcome by mechanical stresses.

Pentagastrin (Peptavlon) was kindly supplied by Dr John D. Stevens of Ayerst Laboratories, New York, NY.

\section{References}

Beiles, B., Picker, S., and Bremner, C. G. (1972). The effect of intragastric aluminum hydroxide on lower oesophageal sphincter pressures. South African Medical Journal, 46, 1387-1389.

Butterfield, D. G., Struthers, J. E. Jr, and Showalter, J. P. (1972). A test of gastroesophageal sphincter competence: The common cavity test. American Journal of Digestive Diseases, 17, 415-421.

Castell, D. O. (1975). The lower esophageal sphincter: physiologic and clinical aspects. Annals of Internal Medicine, 83, 390-401.

Castell, D. O., and Harris, L. D. (1970). Hormonal control of gastroesophageal-sphincter strength. New England Journal of Medicine, 282, 886-889.

Castell, D. O., and Levine, S. M. (1972). Lower esophageal sphincter response to gastric alkalinization: A new mechanism for treatment of heartburn with antacids. Annals of Internal Medicine, 74, 223-227.

Cohen, S., and Harris, L. D. (1971). Does hiatus hernia affect competence of the gastroesophageal sphincter? New England Journal of Medicine, 284, 1053-1056.

Cohen, S., and Lipshutz, W. (1971). Hormonal regulation of human lower esophageal sphincter competence: interaction of gastrin and secretin. Journal of Clinical Investigation, 50, 449-454.

Dodds, W. J., Hogan, W. J., Miller, W. N., Barreras, R. F., Arndorfer, R. C., and Stef, J. J. (1975a). Relationship between serum gastrin concentration and lower-esophageal sphincter pressure. American Journal of Digestive Diseases, 
20, 201-207.

Dodds, W. J., Hogan, W. J., Miller, W. N., Stef, J. J., Arndorfer, R. C., and Lydon, S. B. (1975b). Effect of increased intraabdominal pressure on lower esophageal sphincter pressure. American Journal of Digestive Diseases, 20, 298-308.

Dodds, W. J., Hogan, W. J., Reid, D. P., Stewart, E. T., Arndorfer, R. C., and Malloy, M. (1972). Effects of increased intraabdominal pressure on esophageal motor function. (Abstract) Gastroenterology, 62, 742.

Farrell, R. L., Castell, D. O., and McGuigan, J. E. (1974). Measurements and comparisons of lower esophageal sphincter pressures and serum gastrin levels in patients with gastroesophageal reflux. Gastroenterology, 67, 415-422.

Fyke, F. E., Jr, Code, C. F., and Schlegel, J. F. (1956). The gastroesophageal sphincter in healthy human beings. Gastroenterologia, 86, 135-150.

Giles, G. R., Mason, M. C., Humphries, C., and Clark, C. G. (1969). Action of gastrin on the lower oesophgeal sphincter in man. Gut, 10, 730-734.

Goyal, R. K., and McGuigan, J. E. (1975). Failure of gastrin antiserum to influence lower esophageal sphincter pressure; a double blind controlled study (Abstract). Gastroenterology, 68, 951.

Grossman, M. I. (1973). What is physiological? (Letter). Gastroenterology, 65, 994.

Henderson, R. D., and Rodney, K. (1971). Tone of the gastroesophageal junction: its response to abdominal compression and to swallowing. Canadian Journal of Surgery, 14, 328-334.

Higgs, R. H., Smyth, R. D., and Castell, D. O. (1974). Gastric alkalinization: effect on lower-esophagealsphincter pressure and serum gastrin. New England Journal of Medicine, 291, 486-490.

Ismail-Beigi, F., Horton, P. F., and Pope, C. E. II (1970). Histological consequences of gastroesophageal reflux in man. Gastroenterology, 58, 163-174.

Kaye, M. D., and Showalter, J. P. (1971). Manometric configuration of the lower esophageal sphincter in normal human subjects. Gastroenterology, 61, 213-223.

Lind, J. F., Warrian, W. G., and Wankling, W. J. (1966) Responses of the gastroesophageal junctional zone to increases in abdominal pressure. Canadian Journal of Surgery, 9, 32-38.

Lipshutz, W. H., Gaskins, R. D., Lukash, W. M., and Sode, J. (1973). Pathogenesis of lower-esophageal-sphincter incompetence. New England Journal of Medicine, 289, 182-184.
Lipshutz, W., Hughes, W., and Cohen, S. (1972). The genesis of lower esophageal sphincter pressure: its identifcation through the use of gastrin antiserum. Journal of Clinical Investigation, 51, 522-529.

McCall, I. W., Harvey, R. F., Owens, C. J., and Clendinnen, B. G. (1975). Relationship between changes in plasma gastrin and lower oesophageal sphincter pressure after meals. British Journal of Surgery, 62, 15-18.

Multicentre Pilot Study (1971). Pentagastrin as a stimulant of maximal gastric acid response in man. Lancet, 1, 291.

Nagler, R., and Spiro, H. M. (1961). Segmental response of the inferior esophageal sphincter to elevated intragastric pressure. Gastroenterology, 40, 405-407.

Nebel, O. T., and Castell, D. O. (1972). Lower esophageal sphincter pressure changes after food ingestion. Gastroenterology, 63, 778-783.

Rosenberg, S. J., and Harris, L. D. (1971). Heartburn and hormones: the mechanism of gastro-esophageal sphincter incompetence (Abstract). Gastroenterology, 60, 711.

Siewert, R., Weiser, F., Jennewein, H. M., and Waldeck, F. (1974). Clinical and manometric investigations of the lower esophageal sphincter and its reactivity to pentagastrin in patients with hiatus hernia. Digestion, 10, 287-297.

Sturdevant, R. A. L., and Kun, T. L. (1974). Gastrin and gastroesophageal sphincter incompetence. Proceedings of the Fourth International Symposium on Gastrointestinal Motility, pp. 125-130. Edited by E. E. Daniels et al. Mitchell Press: Vancouver.

Trindade, L. M., Rosenberg, I. L., Rozycki, Z. J., and Giles G. R. (1975). The response of the lower oesophageal sphincter to maximal doses of pentagastrin. British Journal of Surgery, 62, 11-14.

Van Derstappen, G., and Texter, E. C. Jr (1964). Response of the physiologic gastroesophageal sphincter to increased intra-abdominal pressure. Journal of Clinical Investigation, 43, 1856-1868

Waldeck, F. (1972). A new procedure for functional analysis of the lower esophageal sphincter (LES). Pfügers Archiv: European Journal of Physiology, 335, 74-84.

Walker, C. O., Frank, S. A., Manton, J., and Fordtran, J. S. (1975). Effect of continuous infusion of pentagastrin on lower esophageal sphincter pressure and gastric acid secretion in normal subjects. Journal of Clinical Investigation, 56, 218-225.

Wright, L. F., Slaughter, R. L., Gibson, R. G., and Hirschowitz, B. I. (1975). Correlation of lower esophageal sphincter pressure and serum gastrin level in man. American Journal of Digestive Diseases, 20, 603-606. 